\title{
DONOR-SPECIFIC CELLULAR IMMUNE RESPONSE AGAINST HUMAN CARDIAC VALVE ALLOGRAFTS
}

\author{
Franciska Hoekstra, MD \\ Christiaan Knoop, $\mathrm{BSc}^{\mathrm{a}}$ \\ Len Vaessen, BSc ${ }^{\mathrm{a}}$ \\ Claas Wassenaar, $\mathrm{MD}^{\mathrm{b}}$ \\ Nicolet Jutte, $\mathrm{PhD}^{\mathrm{a}}$ \\ Egbert Bos, MD, ${ }^{\mathrm{C}}$ \\ Ad Bogers, $\mathrm{MD}^{\mathrm{c}}$ \\ Willem Weimar, MD ${ }^{\mathrm{a}}$
}

\begin{abstract}
We studied the presence of donor-specific $\mathbf{T}$ lymphocytes in explanted human cardiac valve allografts in vivo. From five of seven explants we propagated lymphocyte cultures in an interleukin-2 conditioned medium. Phenotyping revealed the presence of $T$-cell receptors in more than $95 \%$ of the lymphocytes obtained in each culture. Donor-specific cytotoxicity was demonstrated in three patients with known HLA status of the donor. Cytotoxicity was directed against only HLA class I in one patient, and against class I and/or class II in the others. These results indicate that donor-specific cellular reactivity can be induced by transplantation of human cardiac valve allografts. (J Thorac Cardiovasc Surg 1996;112:281-6)
\end{abstract}

$\mathrm{H}$ uman cardiac valve allografts are transplanted without the immunosuppressive therapy normally given to recipients of vascularized organ transplants because it is supposed that antigenicity does not play a major role. However, early valve failure is not uncommon and, especially in children, other causes besides technical ones are suggested to play a role. ${ }^{1}$ In animal models the antigenicity of valve allografts was illustrated earlier. ${ }^{2,3}$ Sensitization of the recipient against allogeneic valves was revealed by the rejection of donor-specific skin transplants ${ }^{4}$ and by the measurement of allogeneic antibodies. ${ }^{5}$ Recently, a donor-specific cellular immune response in vivo has been demonstrated in rat spleen cells after valve allograft transplantation. ${ }^{6}$ Studies on the antigenicity of human valve allografts have been limited to sparse descriptions of histologic findings of infiltrates in explanted valves. ${ }^{7}$ In addition, we showed stimulation of immune competent cells by human valve leaflets in vitro. ${ }^{8}$

In the present study, we examined the in vivo immune response after transplantation of human cardiac valves. We cultured graft-infiltrating lym-

From the Departments of Internal Medicine I, ${ }^{\text {a }}$ Thorax Center, and Heart Valve Bank, ${ }^{b}$ University Hospital Rotterdam, Rotterdam, The Netherlands.

Received for publication August 14, 1995; revisions requested Oct. 24, 1995; revisions received Jan. 16, 1996; accepted for publication Jan. 18, 1996.

Address for reprints: F. M. E. Hoekstra, MD, Department of Internal Medicine I, Room Bd 293, University Hospital Rotterdam-Dijkzigt, Dr Molewaterplein 40, 3015 GD Rotterdam, The Netherlands.

Copyright 1996 by Mosby-Year Book, Inc.

$0022-5223 / 96 \$ 5.00+0 \quad \mathbf{1 2} / \mathbf{1} / \mathbf{7 2 1 2 3}$ phocytes from explanted human cardiac donor valves and tested them for donor-specific reactivity.

\section{Patients and methods}

Patients. Valve recipients were between 8 months and 60 years of age at the time of transplantation. Valve allografts (four aortic and three pulmonary) were obtained from heart-beating $(n=6)$ and non-heart-beating ( $n=1$, patient 1 ) donors after preparation and cryopreservation according to the Standard Preparation Protocol of the Heart Valve Bank Rotterdam. ${ }^{9}$ Three valves were placed in the aortic position and four were used to reconstruct the right ventricular outflow tract. The interval between transplantation and explantation, the causes of valve failure leading to explantation, and the HLA type of the valve donor are shown in Table I. Four valves were explanted between 19 and 84 months after transplantation because of structural valve failure, which refers to changes intrinsic to the valve, causing stenosis or regurgitation. ${ }^{10}$ One valve was explanted because of nonstructural valve deterioration 6 months after transplantation. Nonstructural dysfunction refers to any abnormality resulting in stenosis or regurgitation that is not caused by intrinsic changes of the valve. Two allografts were explanted for non-valve-related reasons (in one case the allograft was obtained at autopsy after the recipient had died in a car accident, and in the other case it was obtained 4.5 hours after transplantation for technical reasons because of takedown of intracardiac repair). HLA typing of the valve donor was performed on spleen cells or peripheral blood mononuclear cells, isolated on Ficoll-paque $(d=1.077)$ density gradient centrifugation (Pharmacia, Uppsala, Sweden) separation. HLA class I antigens were typed according to the standard National Institutes of Health lymphocytotoxicity assay. Highly selected antisera were used for HLA-DR typing. ${ }^{11}$ The HLA type of the valve recipients was not available. The Medical Ethical Committee of the University Hospital Rotterdam approved the studies.

Culture method. From each explanted valve, the valve leaflets were cut into $2 \mathrm{~mm}$ diameter pieces with a biopsy 
Table I. Patient characteristics

\begin{tabular}{ccccl}
\hline Patient & $\begin{array}{c}\text { Age at time of } \\
\text { transplantation }\end{array}$ & HLA-type donor & Graft & \multicolumn{1}{c}{ Mode of failure } \\
\hline 1 & $25 \mathrm{yr}$ & Unknown & $84 \mathrm{mo}$ & Structural deterioration \\
2 & $8 \mathrm{mo}$ & A1,2 B7,8 DR2,3 & $46 \mathrm{mo}$ & Structural deterioration \\
3 & $35 \mathrm{yr}$ & A2,32 B51 DR11,13 & $6 \mathrm{mo}$ & Nonstructural deterioration \\
4 & $8 \mathrm{yr}$ & $\mathrm{A} 2 \mathrm{~B} 62 \mathrm{DR} 2,4$ & $30 \mathrm{mo}$ & Structural deterioration \\
5 & $60 \mathrm{yr}$ & A2,30 B51,62 DR4 & $5 \mathrm{mo}$ & Nonvalve-related patient death \\
6 & $20 \mathrm{yr}$ & A2 B7,60 DR2,4 & $19 \mathrm{mo}$ & Structural deterioration \\
7 & $4 \mathrm{yr}$ & A1,32 B51,8 DR17,12 & $4.5 \mathrm{hr}$ & Not valve related \\
\hline
\end{tabular}

Table II. Lymphocyte culture characteristics

\begin{tabular}{|c|c|c|c|c|c|c|}
\hline \multirow[b]{2}{*}{ Patient } & \multicolumn{2}{|c|}{ Cell growth } & \multicolumn{2}{|c|}{ Phenotype cultures } & \multicolumn{2}{|c|}{ Donor-specific lysis } \\
\hline & Leaflet & Vessel & Leaftet & Vessel & Leaflet & Vessel \\
\hline 1 & + & ND & $\begin{array}{l}52 \% \text { WT31/CD } 4 \\
46 \% \text { WT31/CD } 8\end{array}$ & & ND & ND \\
\hline 2 & ND & + & & $97 \% \mathrm{WT} 31 / \mathrm{CD} 4$ & & - \\
\hline 3 & + & + & $\begin{array}{l}58 \% \text { WT31/CD } 4 \\
40 \% \text { WT31/CD } 8\end{array}$ & $\begin{array}{l}58 \% \text { WT31/CD } 4 \\
39 \% \text { WT31/CD } 8\end{array}$ & + & + \\
\hline 4 & + & + & $95 \% \mathrm{WT} 31 / \mathrm{CD} 4$ & $\begin{array}{c}57 \% \text { WT31/CD4 } \\
27 \% \text { WT31/CD } 8 \\
15 \% \text { TCR gamma/delta }\end{array}$ & - & + \\
\hline 5 & + & ND & $\begin{array}{l}16 \% \text { WT31/CD4 } \\
83 \% \text { WT31/CD } 8\end{array}$ & & + & - \\
\hline 6 & - & ND & & & & \\
\hline 7 & - & ND & & & & \\
\hline
\end{tabular}

$N D$, Not done; $T C R$, T-cell receptor.

punch (Stiefel Laboratories Ltd., Woodwin Green Bucks, United Kingdom). These pieces were placed in 96-well round-bottomed tissue culture plates (Costar 3799, Corning Costar Corp., Cambridge, Mass.) with $200 \mu$ l culture medium, which consisted of RPMI 1640 Dutch Modification (Gibco Laboratories, Paisley, Scotland) supplemented with $10 \%$ heat-inactivated human serum, $10 \%$ vol/vol lectin-free Lymphocult-T-LF medium (Biotest Pharma $\mathrm{GmbH}$, Dreieich, Germany), an exogenous source of interleukin-2, L-glutamine $4 \mathrm{mmol} / \mathrm{L}$, penicillin $100 \mathrm{IU} / \mathrm{ml}$, and streptomycin $100 \mu \mathrm{g} / \mathrm{ml}$. Irradiated (40 Gy) autologous or third-party peripheral blood mononuclear cells $\left(1.10^{5}\right.$ cells per well) served as feeder. Peripheral blood mononuclear cells were isolated on Ficollpaque. The cultures were grown at $37^{\circ} \mathrm{C}$ in a humidified atmosphere with $5 \%$ carbon dioxide, and every 2 to 3 days half the medium was replaced by fresh culture medium. When growth of lymphocytes was observed, the pieces were removed and the contents of several wells were pooled. When sufficient cell density was reached, the contents of the wells were transferred to more wells.

Phenotypic analysis. T-cell lines were analyzed by three-color flow cytometry for the expression of cell surface antigens after staining with monoclonal antibodies. A pan T-cell marker, WT31, recognizing T-cell receptor alpha/beta, was used, and anti-Leu-3 (CD4) and anti-Leu-2 (CD8) were used as T-cell subset markers.
Anti-Leu-19 (CD56) and anti-Leu-11 (CD16) were used as markers for natural killer cells, and $11 \mathrm{~F} 2$ was used as marker for T-cell receptor gamma/delta expression. Antibodies were directly conjugated to fluorescein isothiocyanate, phycoerythrin, or peridenin chlorophyll protein (Becton Dickinson \& Co., Mountain View, Calif.). A total of $5.10^{4}$ cells were incubated with fluoresceinated monoclonal antibodies for 30 minutes at room temperature. Cells were subsequently washed in phosphate-buffered saline solution and 5000 cells were analyzed in a lymphocyte gate on an FACScan (Becton Dickinson). Lymphocyte gate was set on forward and sideward light scatter, and cell debris was gated out by a threshold on forward light scatter.

Cell-mediated cytotoxicity. A standard 4-hour chromium 51 release assay ${ }^{12}$ was performed to measure the cytotoxic capacity of the cultures against a panel of target cells, sharing one or more HLA antigens with the valve donor. Three types of target cells were used: phytohemagglutinin-blasts as target for activity against HLA class I antigens, Epstein-Barr virus transformed B-cell lines as targets for class I and class II antigens, and the K562 and Daudi cell lines as control for natural killer cell and lymphokine-activated killer cell activity.

A total of $3.10^{3}{ }^{51} \mathrm{Cr}$-labeled target cells per well were placed in 96-well round-bottomed culture plates, and effector cells were added at an effector target ratio from 


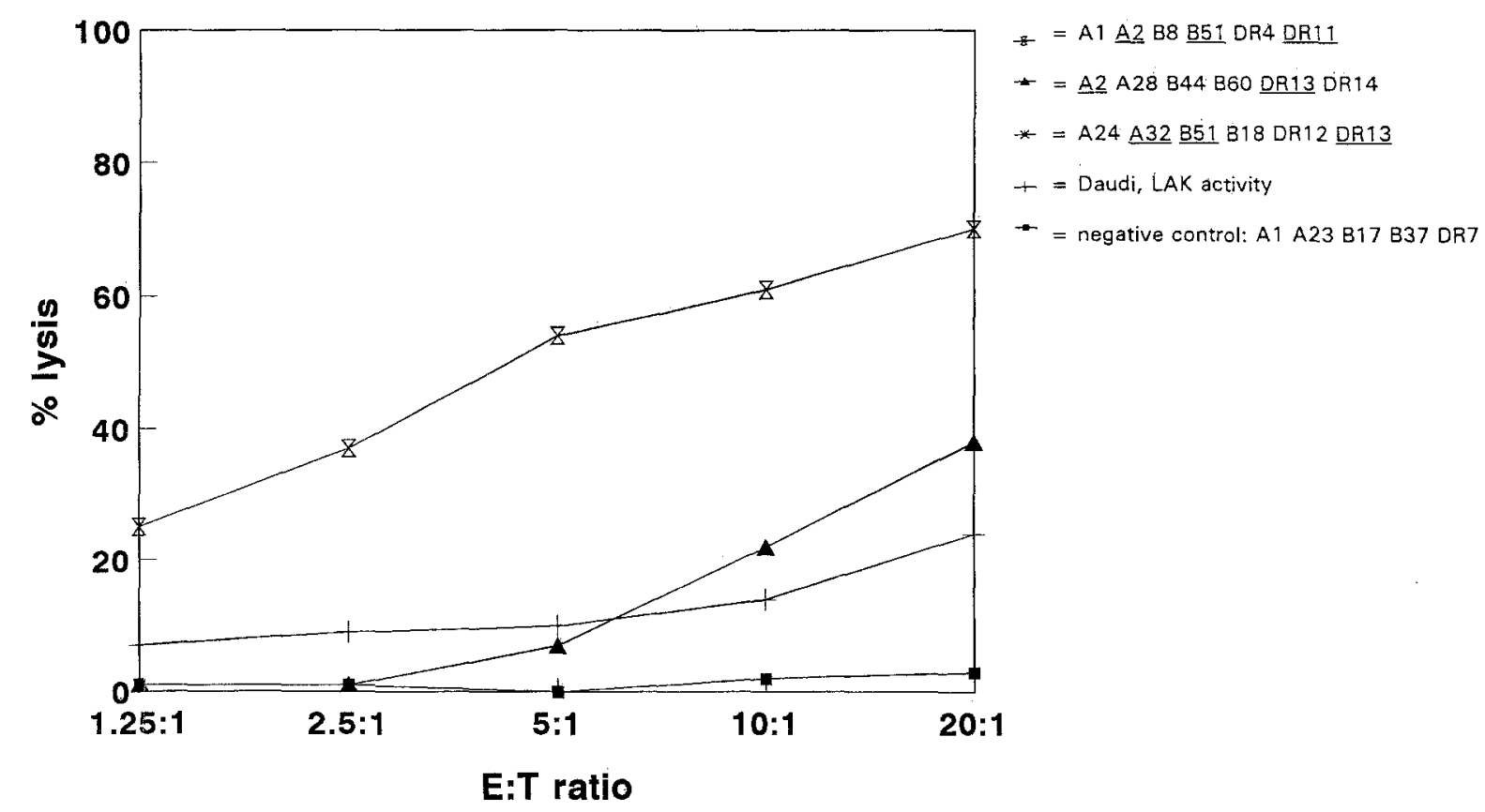

Fig. 1. Donor-specific lympholysis by valve allograft infiltrating cells. Patient 3: lymphocyte cultures derived from the vessel wall. HLA antigens that are matched with valve donor antigens are underlined in the key. $L A K$, lymphokine-activated killer cell.

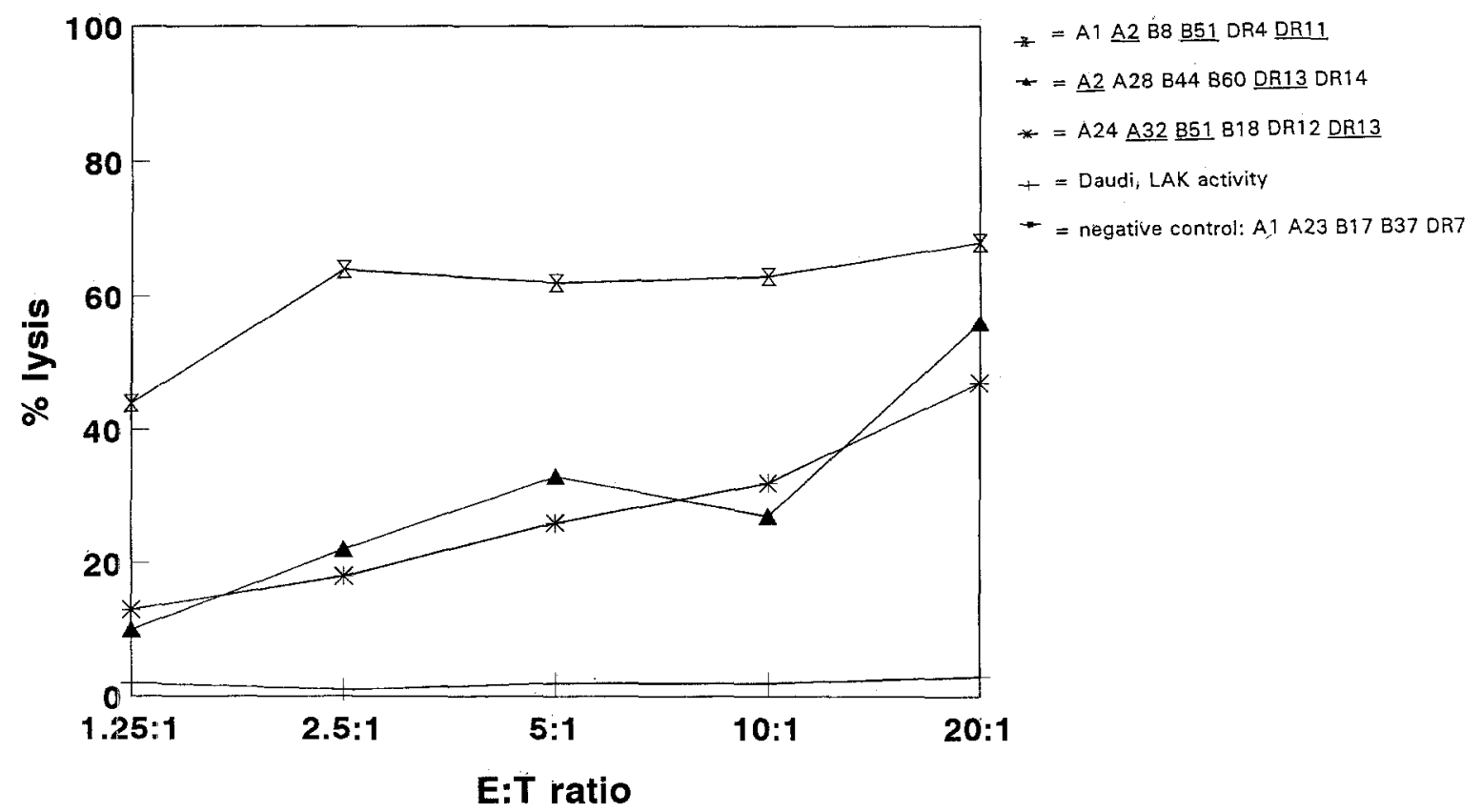

Fig. 2. Donor-specific lympholysis by valve allograft infiltrating cells. Patient 3: lymphocyte cultures derived from the valve leaflet. HLA antigens that are matched with valve donor antigens are underlined in the key. $L A K$, lymphokine-activated killer cell. 


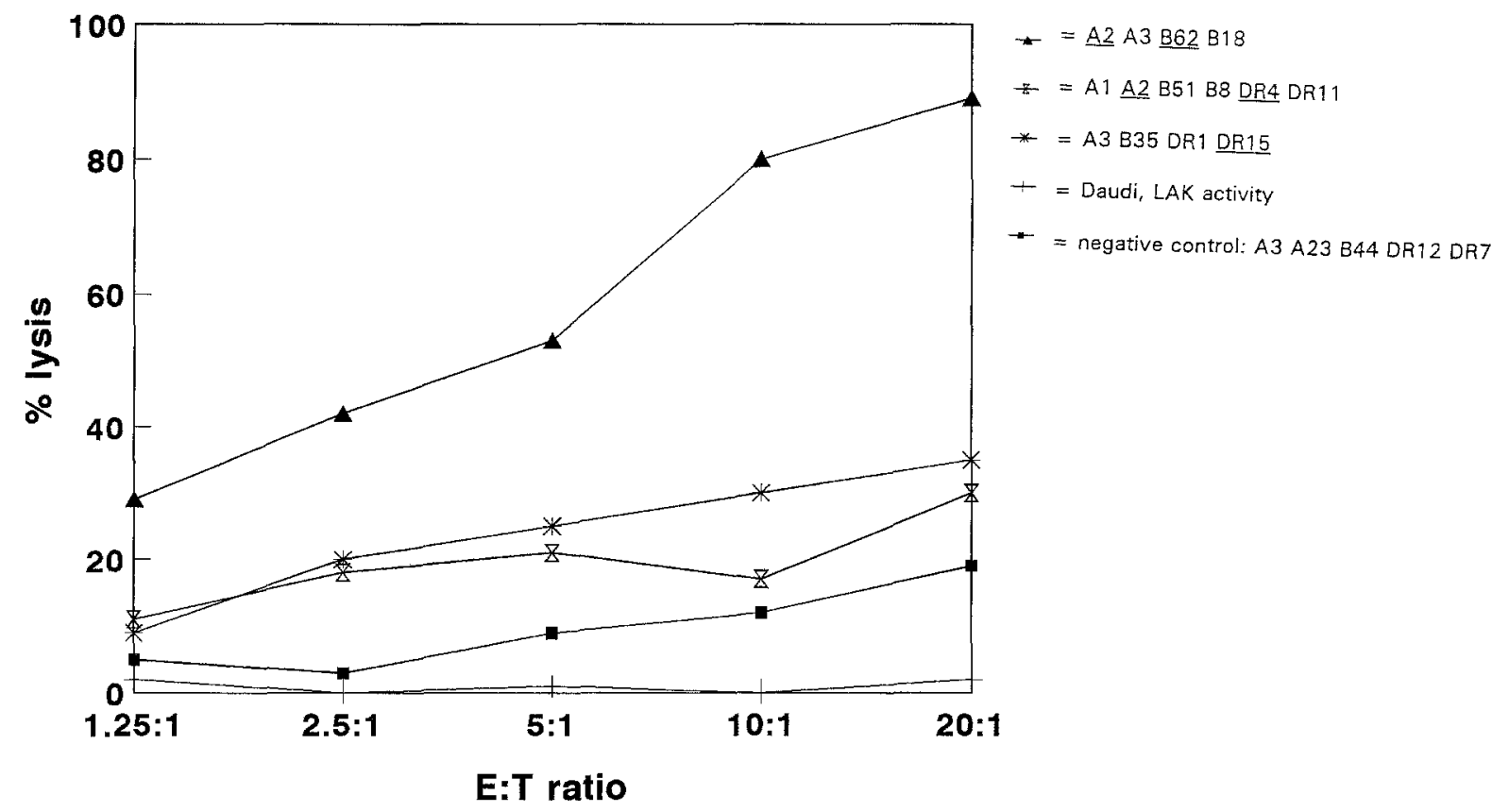

Fig. 3. Donor-specific lympholysis by valve allograft infiltrating cells. Patient 4: lymphocyte cultures derived from the vessel wall. HLA antigens that are matched with valve donor antigens are underlined in the key. $L A K$, lymphokine-activated killer cell.

1:1 to $20: 1$. The plates were centrifuged $(60 \mathrm{~g}, 1$ minute) and incubated for 4 hours at $37^{\circ} \mathrm{C}$ in a humidified atmosphere with 5\% carbon dioxide. Supernatants were collected with a Skatron harvesting system (Skatron A/S, Lierse, Norway) and counted in a gamma counter for 3 minutes. Percentage lysis was calculated according to the formula:

\section{Percent lysis}

$$
=\frac{\text { Experimental release }- \text { Spontaneous release }}{\text { Maximal release }- \text { Spontaneous release }} \times 100
$$

Maximal release was determined in fourfold from an octyphenoxy polyethoxyethanol lysate* of the target cells. Spontaneous release was determined in fourfold by incubation of target cells in medium (RPMI 1640 Dutch Modification, supplemented with $1 \%$ heat-inactivated serum). Cultures were considered cytolytic when the experimental lysis percentage exceeded $10 \%$ at an effector/ target ratio of 20:1 or greater and the slope of the graph was positive. ${ }^{12}$

Numeric results are presented as median with range. Clinical and allograft characteristics were compared with the Wilcoxon test or Student's $t$ test where appropriate. A $p$ value smaller than 0.05 was considered to be significant.

*Triton X 100 (Union Carbide Corp., Danbury, Conn.), 5\% $\mathrm{vol} / \mathrm{vol}$ solution in tromethamine buffer, $0.01 \mathrm{~mol} / \mathrm{L}$.

\section{Results}

Although several explants showed macroscopic and microscopic signs of calcification, lymphocyte cultures were obtained from five of seven available human cardiac donor valves from the valve leaflet or the vessel wall (Table II). These cultures all contained $95 \%$ or more $\mathrm{T}$-cell receptor-bearing cells. The median percentage of CD8 positive lymphocytes in these cultures was $40 \%$ (range $27 \%$ to $83 \%$ ), and the median percentage of CD4 positive lymphocytes was 58\% (range 16\% to 97\%) (Table II). One lymphocyte culture was obtained from a valve of which the HLA status of the donor was not available and could not be tested for donor specificity in a cell-mediated lympholysis assay. One allograft had been transplanted for only 4.5 hours and served as a control for the test system. This valve explant indeed did not generate a lymphocyte culture. Finally, six cultures derived from four remaining explants were tested in a cell-mediated lympholysis assay against a panel of target cells sharing one or more HLA antigens with the valve donor. More than $60 \%$ lysis of cells sharing HLA antigens with the valve donor was observed in four cultures, derived from three explants (patients 3, 4, and 5, Figs. 1 to 4 ). No 


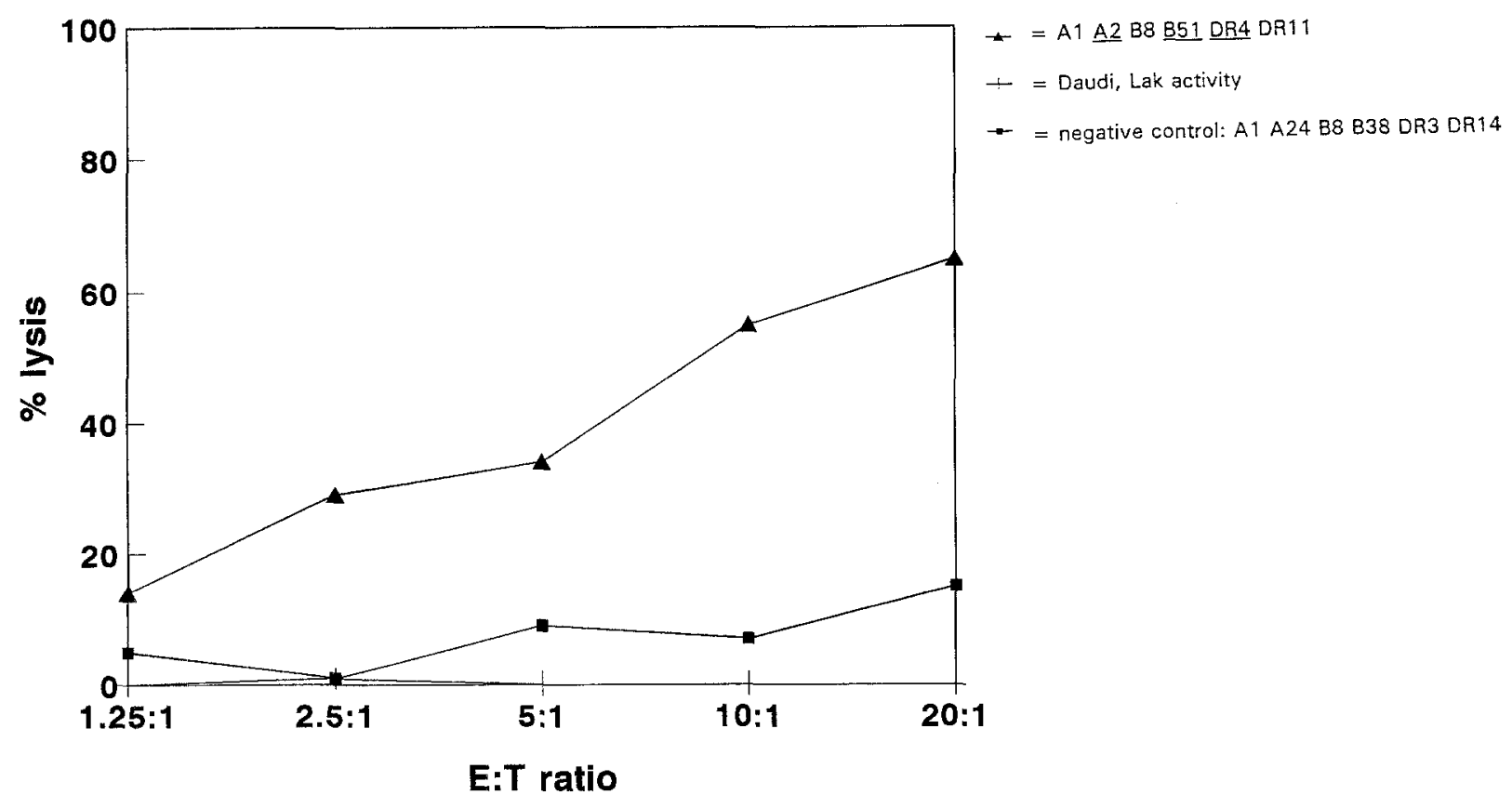

Fig. 4. Donor-specific lympholysis by valve allograft infiltrating cells. Patient 5: lymphocyte cultures derived from the valve leaflet. HLA antigens that are matched with valve donor antigens are underlined in the key. $L A K$, lymphokine-activated killer cell.

correlation was found between explants showing donor-specific lysis, age at the time of implantation, graft survival, or mode of failure. In patient 2 the culture consisted of CD4 positive cells only and showed no cytotoxic reactivity. As shown in Table II, in two cases lymphocyte cultures were generated from both valve leaflet and vessel wall (patients 3 and 4). The phenotype of the two cultures derived from the allograft and vessel wall in patient 3 were identical, whereas the phenotype of these two cultures differed in patient 4.

As negative controls, third-party cells (sharing no HLA antigens with the donor) were used in the cytotoxicity test. These cells were not lysed, and in addition both natural killer cell and lymphokineactivated killer cell activity remained within relatively low ranges (Figs. 1 to 4). According to these results, cytotoxicity of the recipient lymphocytes was documented against class I antigens of the donor in one patient (patient 4), whereas in the other two patients cytotoxicity might be directed against class I or class II antigens, or both.

\section{Discussion}

From earlier in vitro and experimental animal studies it was clear that cardiac valve allografts are able to stimulate the immune system..$^{2-6}$ In the present study, we showed for the first time in a functional way that after valve allograft transplantation, cytotoxic lymphocytes are generated in at least some allografts (five of six in our study) that are specifically directed against donor antigens. We cultured alloreactive $T$ cells in interleukin-2 conditioned medium, in which only activated interleukin-2 receptor bearing lymphocytes are supposed to grow. Similar immunologic methods have already been applied to characterize graft-infiltrating cells after solid organ transplantation. ${ }^{13-15}$ In these reports a correlation between the presence of donorspecific cytotoxic $T$ cells in the graft and rejection was described, confirming the clinical relevance of these studies. The small number of our presentseries cardiac valve allografts prohibits us from making a correlation between in vivo data and patient characteristics. Nevertheless, our study unequivocally demonstrates lymphocytes infiltrating the transplanted valve, which may lead to immunologic inflammation, potentially resulting in tissue damage and thus allograft dysfunction. Endothelial cells probably play a key role in this process. Previously we showed that valve endothelial cells are able to induce lymphoproliferation, and heart endothelial cells can also be targets for cytotoxic lymphocytes. $^{16,17}$ We also detected antibodies against do- 
nor HLA in 14 of $21(67 \%)$ living patients with the allograft valve in place. Although valve allograft dysfunction does not necessarily result in cardiac failure, a significant number of valve replacements is necessary, especially in young recipients. ${ }^{1}$

In conclusion, our study shows that donor-directed immune mechanisms are among the factors possibly leading to tissue damage and valve allograft failure. Prospective immunologic monitoring is needed to assess the relative importance of this particular factor. Manipulation of the allograft to reduce the antigenicity should be considered, and indeed, cryopreservation is associated with a lower immunogenicity than fresh valve allografts. ${ }^{8}$ In the present study we found activity against class I and class II antigens, and we already showed in vitro evidence for the importance of class II matching, ${ }^{8}$ which could be considered in individual patients in case of second valve replacements and in children with their high risk of valve failure. Alternatively, low-dose immunosuppression could be given to patients in whom the risk of valve failure is high, ${ }^{1}$ but only for a short while, because complications of long-term immunosuppression may not outweigh its benefits.

\section{REFERENCES}

1. Clarke DR, Campbell DN, Hayward AR, Bishop DA. Degeneration of aortic valve allografts in young recipients. $J$ Thorac Cardiovasc Surg 1993; 105:934-42.

2. Gonzalez-Lavin L, Bianchi J, Graf D, Amini S, Gordon CI. Degenerative changes in fresh aortic root homografts in a canine model: evidence of an immunologic influence. Transplant Proc 1988;20(suppl 1):815-9.

3. Lupinetti FM, Cobb S, Kioschos HC, et al. Effect of immunological differences on rat aortic valve allograft calcification. J Card Surg 1992;7:65-70.

4. Khatib H, Lupinetti FM. Antigenicity of fresh and cryopreserved rat valve allografts. Transplantation 1990;49:756-67.

5. Thiede A, Timm C, Bernhard A, Müller-Ruchholz W. Studies on the antigenicity of vital allogenic valve leaflet transplants in immunogenetically controlled strain combinations. Transplantation 1978;26:391-5.
6. Zhao X, Green M, Frazer IH, Hogan P, O'Brien MF. Donor-specific immune response after aortic valve allografting in the rat. Ann Thorac Surg 1994;57:1158-63.

7. Yankah AC, Wottge HU, Muller-Hermeling $\mathrm{HK}$, et al. Transplantation of aortic and pulmonary allografts, enhanced viability of endothelial cells by cryopreservation, importance of histocompatibility. J Card Surg 1987;1(suppl): 209-20.

8. Hoekstra F, Knoop C, Wassenaar C, Jutte N, Bos E, Weimar W. The effect of cryopreservation and HLA DR matching on the cellular immunogenicity of human cardiac valve allografts. J Heart Lung Transplant 1994;13:1095-8.

9. Lange PL, Hopkins RA. Allograft valve banking: techniques and technology. In: Hopkins RA, editor. Cardiac reconstructions with allograft valves. New York: Springer-Verlag, 1989: 37-63.

10. Edmunds LH, Clark RE, Cohn LH, Miller DC, Weisel RD. Guidelines for reporting morbidity and mortality after cardiac valvular operations. J Thorac Cardiovasc Surg 1988;96: 351-3.

11. van Rood JJ, van Leeuwen A, Ploem JS. Simultaneous detection of two cell populations by two-colour fluorescence and application to the recognition of B-cell determinants. Nature 1976;262:795-7.

12. Human histocompatibility testing by T-cell mediated lympholysis. A European CML standard technique. Report from the European CML workshop. Tissue Antigens 1980;16:33567.

13. Mayer TG, Fuller AA, Fuller TC, Lazarovits AI, Boyle LA, Kurnick JT. Characterization of in vivo-activated allospecific T lymphocytes propagated from human renal allograft biopsies undergoing rejection. J Immunol 1985;134:258-64.

14. Zeevi AJ, Fung TR, Zerbe C, et al. Allospecificity of activated $\mathrm{T}$ cells grown from endomyocardial biopsies from heart transplant patients. Transplantation 1986;41:620-6.

15. Ouwehand AJ, Vaessen LMB, Baan CC, et al. Alloreactive lymphoid infiltrates in human heart transplants: loss of class II directed cytotoxicity more than three months after transplantation. Hum Immunol 1991;30:50-9.

16. Hoekstra F, Knoop C, Wassenaar C, Jutte N, Mochtar B, Bos $\mathrm{E}$, et al. Stimulation of immune competent cells in vitro by human cardiac valve derived endothelial cells. Ann Thorac Surg 1995;60:131-4.

17. Jutte NHPM, Heijse P, van Batenburg MH, et al. Donor heart endothelial cells as targets for graft infiltrating lymphocytes after clinical cardiac transplantation. Transplant Immunol 1993;1:39-44. 